\section{Etiología y perfil de resistencia antimicrobiana en infección del tracto urinario en niños, Valdivia 2012}

\author{
Carolina Herrera, Diego Navarro y Marlis Täger
}

Etiology and antimicrobial resistance profile of urinary
tract infection in children, Valdivia 2012

Introduction: Since initial antibiotic treatment in patients with urinary tract infection (UTI) is empiric, is very important to know the local epidemiology to make the correct therapeutical decisions. Objective: Determinate local features of antimicrobial resistance in pediatric patients with UTI. Method: Retrospective review of urine culture tests of children under 15 years old, obtained in a pediatric emergency department in Valdivia, between february and december 2012. Results: Escherichia coli showed high percentage of resistance to ampicillin $(44,8 \%)$ and first generation cephalosporin (36\%). Discussion: A well understanding of local antimicrobial resistance profile is useful to a correct empiric treatment.

Key words: Urinary tract infections, pediatrics, antimicrobial drug resistance.

Palabras clave: Infecciones del tracto urinario, pediatría, resistencia a antimicrobianos.

\section{Introducción}

La infección del tracto urinario (ITU) es la segunda causa más frecuente de infección bacteriana en niños ${ }^{1}$. Su tratamiento inicial es frecuentemente empírico, por lo que la elección del antimicrobiano se basa en la epidemiología y patrones de susceptibilidad locales. Con el objetivo de conocer la etiología y perfil de resistencia antimicrobiana de uropatógenos en pacientes pediátricos ambulatorios con infección del tracto urinario, se realizó esta revisión retrospectiva en el Hospital de Valdivia, durante el año 2012.

\section{Método}

Revisión retrospectiva de resultados de urocultivos realizados a pacientes consultantes en el Servicio de Urgencia Pediátrico del Hospital de Valdivia, entre febrero y diciembre de 2012, en menores de 15 años con sospecha de ITU.

\footnotetext{
Universidad Austral de Chile.

Programa de Internado de Medicina (CH, DN).

Infectología (MT).

Conflictos de interés: no existieron conflictos de interés

Fuente de financiamiento: Sin entidades patrocinadoras; auspicio Instituto Pediatría, Universidad Austral de Chile.

Recibido: 12 de junio de 2014 / Aceptado: 15 de julio de 2014

Correspondencia a:

Carolina Herrera A.

carolidiss@gmail.com
}

\section{Resultados}

Se obtuvieron en total 1.768 urocultivos; de los cuales $346(19,6 \%)$ fueron positivos; $1.044(62,4 \%)$ negativos y $318(18 \%)$ catalogados como "contaminados" (recuentos $>100.000 \mathrm{ufc} / \mathrm{ml}$ con desarrollo de tres o más microorganismos, sin predominio de alguno).

De los urocultivos positivos $(\mathrm{n}=346)$ el agente más frecuentemente aislado fue Escherichia coli $(\mathrm{n}=281)$ representando $81,2 \%$ del total; Proteus spp. (6,9\%), Staphylococcus spp. (2,3\%), Enterococcus faecalis (2\%), Serratia spp. $(1,7 \%)$ y Klebsiella spp. $(0,6 \%)$.

Escherichia coli presentó $44,8 \%$ de resistencia a ampicilina; $36 \%$ a cefalosporinas de primera generación; $2,2 \%$ a cefalosporinas de segunda generación y $2,5 \%$ a cefalosporinas de tercera generación; $2,5 \%$ a quinolonas; $3,5 \%$ a nitrofurantoína; $5,7 \%$ a aminoglucósidos y $8,3 \%$ a cotrimoxazol. Sólo $2 \%(\mathrm{n}=7)$ fue productor de betalactamasas de espectro extendido (BLEE), correspondiendo todos los aislados a E. coli. Proteus spp. presentó $20,9 \%$ de resistencia a ampicilina; $4,2 \%$ a cefalosporinas de primera y $16,7 \%$ a cefalosporinas de segunda generación; $83,4 \%$ a nitrofurantoína y $16,7 \%$ a cotrimoxazol.

\section{Discusión}

Los microorganismos más frecuentemente aislados correspondieron a $E$. coli y Proteus spp. $(88,1 \%)$, acorde a lo descrito en la literatura científica ${ }^{2-6}$.

Escherichia coli sigue siendo el principal agente etiológico de ITU en pediatría (70-90\% de los casos) según nuestra revisión, por lo que su patrón de susceptibilidad determina habitualmente la elección empírica de la antibioterapia.

En nuestro medio, E. coli representó $81,2 \%$ de los uropatógenos aislados, con un alto porcentaje de resistencia a ampicilina y a cefalosporinas de primera generación. Estos datos son preocupantes puesto que son, con frecuencia, el antimicrobiano de uso empírico para el manejo de ITU, alcanzando una resistencia superior a $30 \%$ en pacientes ambulatorios, hecho similar a lo descrito en otros estudios nacionales ${ }^{2,7}$.

La frecuencia de resistencia de $E$. coli a cotrimoxazol ha disminuido en los últimos años, y en nuestro medio la susceptibilidad supera $90 \%$ por lo que podría ser un antimicrobiano a reconsiderar en esta patología. Nitrofurantoína figura también con excelente sensibilidad, pero debemos recordar que su uso está limitado a infección urinaria baja y profilaxis en los casos con indicación.

Proteus spp. evidenció un alto porcentaje de resistencia a nitrofurantoína, concordante con lo descrito por R. Camponovo en $2007^{2}$. En nuestra localidad, también se evidenció mayor resistencia de este microrganismo a ampicilina, cefalosporinas de segunda generación y cotrimoxazol.

Las cepas de E. coli productoras de BLEE (2,5\%) aparecen como patógenos emergentes en las ITUs adquiridas por niños en la comunidad. Esto obliga a los clínicos a estar informados y saber que estas enzimas confieren resistencia a penicilinas, cefalosporinas y aztreonam, por lo que una cepa productora de BLEE debe considerarse resistente a todos los betalactámicos, con excepción de los carbapenémicos, aunque sean susceptibles in vitro ${ }^{8}$.

\section{Referencias bibliográficas}

1.- Gallegos J, Márquez S, Morales K, Peña A. Perfil etiológico y susceptibilidad antimicrobiana del primer episodio de infección urinaria febril. Rev Chilena Infectol 2013; 30: 474-9.

2.- Camponovo R. Susceptibilidad bacteriana a antimicrobianos. Especies aisladas en pacientes ambulatorios de la Región Metropolitana, Chile 2007. Rev Chilena Infectol 2009; 26: 18-20. 
3.- Hernández R, Daza A, Marín J. Infección urinaria en el niño (1 mes-14 años). Asociación Española de Pediatría 2008. Protocolos actualizados año 2008. Disponible: http://www.aeped.es/sites/default/files/ documentos/5_4.pdf. (accedido: 23 de agosto de 2014).

4.- Catal F, Bavbek N, Bayrac O, Karabel M, Karabel D, Odemis E, et al. Antimicrobial resistance patterns of urinary tract pathogens and rationale for empirical therapy in Turkish children for the years 2000-2006. Int Urol Nephrol 2009; 41: 953-7.

5.- Bronzwaer S L, Cars O, Buchholz U, Mölstad S, Goettsch W, Veldhuijzen I K, et al. A European study on the relationship between antimicrobial use and antimicrobial resistance. Emerg Infect Dis 2002; 8; 278-82.

6.- Rempel O R, Laupland K B. Surveillance for antimicrobial resistant organisms: potential sources and magnitude of bias. Epidemiol Infect 2009; 137: 1665-73.

7.- Lizama M, Luco M, Reichhard T, Hirsch T. Infección del tracto urinario en un servicio de urgencia pediátrico: frecuencia y características clínicas. Rev Chilena Infectol 2005; 22: 235-41.

8.- García P. Resistencia bacteriana en Chile. Rev Chilena Infectol 2003; 20 (Supl 1): S11-S23. 